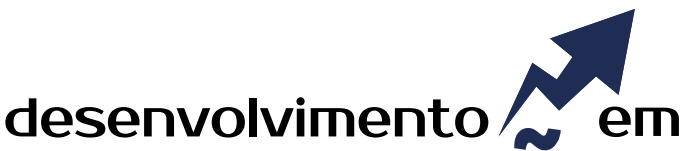 QUESTÃO
}

\section{Artesanato, Identidade Cultural e Mercado Simbólico Dinâmica da Vila Progresso em Caçapava do Sul-RS}

\author{
http://dx.doi.org/10.21527/2237-6453.2019.49.191-208
}

Recebido em: $28 / 11 / 2018$

Aceito em: 28/5/2019

Daiane Loreto de Vargas ${ }^{1}$, Marco Antônio Verardi Fialho²

\begin{abstract}
RESUMO
As pesquisas sobre os elementos culturais e simbólicos que compõem os diferentes territórios têm ganhado destaque nas ciências sociais. No contexto do pampa gaúcho destacam-se os estudos sobre os saberes tradicionais das comunidades rurais e as dinâmicas comerciais dos artigos artesanais, como as confeç̧ões produzidas artesanalmente em lã. A produção artesanal pode estar relacionada aos aspectos tradicionais de uma determinada região, "re"produzindo elementos identitários de uma cultura por meio da confecção e comercialização de produtos simbólicos. Para compreender tais questões, tomou-se por base a dinâmica comercial dos produtos artesanais confeccionados pelos artesãos da comunidade rural da Vila Progresso em Caçapava do Sul - RS. Nesse sentido, este trabalho tem por objetivo entender como desenvolveu-se a dinâmica comercial dos artigos artesanais produzidos e comercializados no local. Metodologicamente, a pesquisa constituiu-se a partir de um estudo de caso de caráter exploratório e descritivo, com uma abordagem qualitativa. Como referencial teórico foram utilizados, especialmente, as publicações de Canclini (1983), Bourdieu (2007), Tedesco (2013), Rieth et al. (2014) e Rieth e Lima (2018). Os principais resultados mostram que a comercialização dos produtos artesanais na comunidade estudada passou por um processo de crescimento e diversificação, tendo em vista a evolução do cenário cultural e simbólico dos produtos artesanais gauchescos, bem como a valorização dos saberes tradicionais no contexto do mercado consumidor.
\end{abstract}

Palavras-chave: Artesanato. Comercialização. Cultura. Simbologias.

\section{HANDICRAFTS, CULTURAL IDENTITY AND SYMBOLIC MARKET: DYNAMICS OF VILA PROGRESSO IN CAÇAPAVA DO SUL-RS}

\begin{abstract}
Research on the cultural and symbolic elements that make up the different territories has gained prominence in the social sciences. In the context of the pampa of the state of Rio Grande do Sul, we highlight the studies on the traditional knowledge of rural communities and the commercial dynamics of handicrafts, such as handicrafts produced in wool. Craft production may be related to the traditional aspects of a given region, "re" producing identity elements of a culture through the making and marketing of symbolic products. In order to understand these issues, the commercial dynamics of handicrafts made by the artisans of Vila Progresso's rural community in Caçapava do Sul - RS were taken as a basis. In this sense, this work aims to understand how the commercial dynamics of handicrafts produced and marketed locally developed. Methodologically, the research was based on an exploratory and descriptive case study, with a qualitative approach. As a theoretical reference, the publications of Canclini (1983), Boudieu (2007), Tedesco (2013), Rieth et al. (2014) and Rieth and Lima (2018) were used. The main results point out that the commercialization of artisanal products in the studied community underwent a process of growth and diversification, taking into account the evolution of the cultural and symbolic scenario of gauchesque artisan products, as well as the appreciation of traditional knowledge in the context of the consumer market.
\end{abstract}

Keywords: Craft. Marketing. Culture. Symbologies.

\footnotetext{
${ }^{1}$ Doutora em Extensão Rural pela Universidade Federal de Santa Maria (UFSM). Professora-adjunta do Centro de Ciências Agrárias Ambientais e Biológicas (CCAAB) da Universidade Federal do Recôncavo da Bahia (UFRB). loretodevargas@gmail.com

2 Doutor em Desenvolvimento, Agricultura e Sociedade pela Universidade Federal Rural do Rio de Janeiro (UFRRJ). Professor da Universidade Federal de Santa Maria (UFSM). marcoavf@hotmail.com
} 
No passado os produtos artesanais eram necessários para os afazeres básicos e para as atividades da vida cotidiana de homens e mulheres. Na atualidade, estes artigos adquiriram novas conotações, e muitos dos quais foram ressignificados para um novo contexto, passando a serem requisitados no mercado contemporâneo tendo em vista seu aspecto histórico e cultural. Nesse sentido, as peças artesanais podem ser apreciadas no mercado em virtude do artesão, que confecciona detalhadamente cada artigo, e que ali expressa um pouco de suas memórias, vivências e saberes, assim como pelo fato de serem objetos diferenciados dos produtos industrializados. Os artigos artesanais são apreciados por certos grupos de consumidores que valorizam aspectos culturais e de identidade territorial, em contrapartida aos produtos de consumo de massa.

Considerando estas questões, a comercialização dos objetos artesanais no mercado ocorre pelo fato de estes possuírem a combinação entre valor econômico e cultural. Agregado ao valor econômico, o valor cultural soma-se ao primeiro pela construção sociocultural de um determinado grupo social, que consome esses artigos artesanais com objetivo de legitimação e diferenciação, fortemente ligado ao processo histórico e identitário do Rio Grande do Sul. Esse processo de confecção artesanal imprime parte de sua história tanto no produto confeccionado quanto no próprio processo de confecção artesanal (CANCLINI, 1983). No que se refere aos aspectos culturais, cabe destacar que tais elementos passaram a comunicar aspectos da tradição de determinados territórios, e fazem parte de um patrimônio imaterial de um povo ou comunidade. São essas diferenciações que levam os artigos a serem interpretados e negociados como mercadorias simbólicas (BOURDIEU, 2007; DOUGLAS; ISHERWOOD, 2006).

A partir de reflexões como estas, as pesquisas sobre os elementos culturais e simbólicos que compõem os diferentes territórios têm ganhado destaque nas ciências sociais. No contexto do Rio Grande do Sul, por exemplo, destacam-se os estudos de Tedesco (2013), Rieth et al. (2014), Rieth e Lima (2018), Vargas (2016) e Vargas e Fialho (2018), sobre os saberes tradicionais das comunidades rurais e as dinâmicas comerciais dos artigos artesanais, como as confecções produzidas artesanalmente em lã. Destaca-se que a produção artesanal pode estar relacionada aos aspectos tradicionais de uma determinada região, "re"produzindo elementos identitários de uma cultura por intermédio da confecção e comercialização de produtos simbólicos.

Nesse sentido, o problema que orienta este estudo diz respeito à compreensão de como se desenvolveu a dinâmica comercial dos artigos artesanais confeccionados pelos artesãos da comunidade rural da Vila Progresso, localizada em Caçapava do Sul RS (Figura 1). O município, distante $250 \mathrm{~km}$ de Porto Alegre, está localizado na Serra do Sudeste, território do pampa. Possui proximidade com as BRs-392, 153 e 290, em que está localizada a comunidade, caracterizando-se geograficamente como um caminho de passagem aos países do Mercosul (PETRIN; CARMO DA SILVA, 2013).

A comunidade referida fica distante aproximadamente $25 \mathrm{~km}$ da cidade, e sua localização contribui para a estruturação comercial de pontos de vendas das peças tradicionais e culturais da região do pampa: as tendas comerciais. Este fato facilita a negociação dos artigos artesanais confeccionados no local, como palas, ponchos, xergão, mantas, xales, dentre outros. Tais peças, inicialmente, eram produzidas pelas mulheres 
artesãs e, atualmente, com o crescimento da atividade do mercado simbólico dos produtos gauchescos, configura-se como um trabalho realizado por homens e mulheres da comunidade (VARGAS; FIALHO, 2018).

Figura 1 - Mapa de localização de Caçapava do Sul-RS

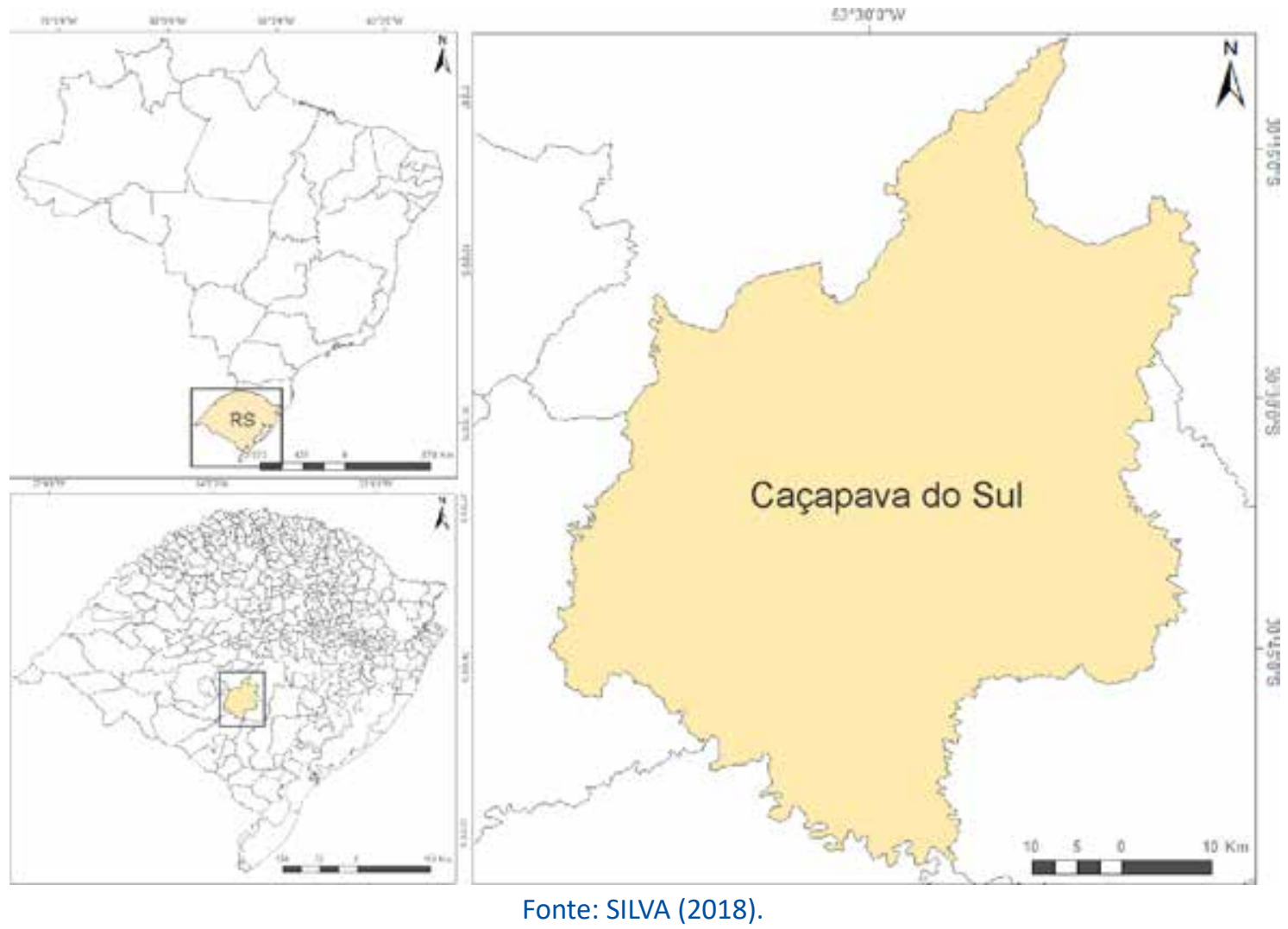

Além do fator localização, a dinâmica comercial na Vila Progresso também é favorecida em razão de a mesma estar em um contexto que possui fortes elementos históricos e culturais, tais como o clima frio, a lida campeira, os campos de pedra, a criação de gado e ovelha, os saberes e os fazeres das mulheres rurais com a lã, além do fato de a região ter sido palco de batalhas da Revolução Farroupilha (1835-1845), todos eles constituidores da identidade pampiana e, consequentemente, gaúcha.

Assim, o território sulino abriga diversos fatores que colaboraram para a formação histórica e cultural das comunidades que nele habitam, desde as paisagens naturais, os aspectos do clima, as práticas e os saberes culturais. Esse conjunto de fatores contribui para a formação das "tradições" que forjaram a identidade e o território do Estado do Rio Grande do Sul. Estes são alguns dos subsídios que colocam a região como promissora na prática e no saber do artesanato tradicional em lã e couro. Nesse sentido, a comunidade destaca-se no cenário de confecção e comercialização de artigos artesanais, e tais atividades configuram-se como a principal dinâmica econômica do local.

Com o objetivo de entender a dinâmica comercial dos produtos artesanais confeccionados pelos artesãos da comunidade de Vila Progresso, este estudo procurou identificar a origem da atividade do artesanato e seu processo de desenvolvimento, atentando para o mercado local (venda na beira da estrada) e, posteriormente, para outras regiões do Rio Grande do Sul. Nesse processo de desenvolvimento da produção 
e comercialização dos artigos artesanais, o estudo focou no mercado e na utilização de mão de obra local, a qual foi importante para sustentar o desenvolvimento de novos produtos e a demanda crescente do mercado. A investigação contemplou a localidade de Vila Progresso e Feiras Agropecuárias, as quais foram visitadas, para a realização da pesquisa de campo, entre os anos de 2014 e 2016.

Metodologicamente, a pesquisa ${ }^{3}$ configura-se como um estudo de caso, o qual teve um caráter qualitativo e um enfoque socioantropológico embasado em autores como Canclini (1983), com "As culturas populares no capitalismo", Bourdieu (2007), com "A economia das trocas simbólicas", Tedesco (2013), em seus estudos sobre os tendeiros do centro-norte do Rio Grande do Sul e em Rieth et al. (2014) e Rieth e Lima (2018), em suas pesquisas sobre as "Lidas Campeiras", as quais passaram a ser interpretadas como um patrimônio imaterial do pampa, portanto, parte da identidade cultural desse território.

Este estudo configura-se como de caráter etnográfico. Os métodos utilizados para a coleta de dados foram a entrevista semiestruturada, a prática da observação, fotografia e o diário de campo. Num primeiro momento foram entrevistadas 16 famílias de artesãos da comunidade, ou seja, todas as famílias que possuíam tendas comerciais no local, e, num segundo momento, foram realizadas entrevistas em profundidade com 8 famílias, e a seleção destas ocorreu em razão da qualidade das informações adquiridas na primeira entrevista.

Para responder ao objetivo proposto, além da parte introdutória, o presente artigo foi estruturado em seções. Na sequência aborda-se sobre o artesanato tradicional no Rio Grande do Sul. A seguir contextualiza-se a identidade cultural e o mercado simbólico dos produtos artesanais no território do pampa. Para finalizar analisa-se as dinâmicas comerciais do artesanato na comunidade rural da Vila Progresso, e destaca-se algumas considerações finais e as referências bibliográficas.

\section{ARTESANATO TRADICIONAL NO RIO GRANDE DO SUL}

O fazer manual de cunho tradicional normalmente é produzido por indígenas ou camponeses por meio dos seus saberes, dos aspectos culturais e de suas tradições. São objetos, técnicas de produção e desenhos enraizados na própria história das famílias que criam os artigos (CANCLINI, 1983). Este tipo de produção pouco inova e geralmente é produzido com o trabalho familiar ou da comunidade, favorecendo o processo de transmissão dos conhecimentos, preservando a cultura e divulgando a mesma para as futuras gerações (FILHO, 2009).

No contexto do Rio Grande do Sul, a construção de um referencial sobre o artesanato é um desafio, tendo em vista que os estudos sobre o assunto fazem parte de recortes e conteúdos pouco explicativos. A literatura afirma que o artesanato no Estado possui raízes históricas e traços do saber e da cultura das comunidades, além da influência do contexto climático, geográfico e do modo de vida da sociedade gaúcha no tempo histórico. A criação dos produtos artesanais, num primeiro momento, tinha sentido utilitário para o cotidiano dos indivíduos.

\footnotetext{
${ }^{3}$ Este trabalho é parte de uma pesquisa que deu origem a um trabalho de tese (VARGAS, 2016).
} 
Dessa forma, o cenário do artesanato gaúcho, ao longo de sua história, possui como uma de suas particularidades a criação de objetos e utensílios de cunho "regionalizado" e diversificado, de acordo com as etnias de cada localidade (FAGUNDES, 1995). Alguns dos produtos artesanais mais característicos do Estado estão representados nos hábitos adquiridos pela região do pampa (fronteira oeste ou campanha), com forte influência da cultura e dos saberes indígenas.

Pode-se destacar a confecção artesanal de vários utensílios para as casas ou ranchos, para o trabalho no campo com o gado e agasalhos para se abrigar do frio. Além da lã, vários tipos de matérias-primas foram e ainda são utilizados no Estado para a confeç̧ão de peças artesanais, tais como: crina de animais, metal, ferro, tintura (produzida naturalmente), taquara, porongo e a palha (ZATTERA, 1988). Essas matérias-primas, na maioria das vezes, eram manuseadas pelos artesãos homens.

A autora lembra que com o porongo se cria a cuia de chimarrão, símbolo da cultura gaúcha e da bebida típica do território. Outros exemplos são citados por Fagundes (1995), como o couro bovino, utilizado para a confecção de bainhas de faca, boleadeiras, arreios, botas, guaiacas, malas de garupa e móveis caseiros, como o lastro trançado em couro das camas e os assentos e encostos das cadeiras. Também os chifres dos animais, utilizados para a criação de produtos como: cabos de facas, de chairas e de canivetes (FAGUNDES, 1995).

Já as peças confeccionadas artesanalmente em lã, por exemplo, começaram a ser produzidas a partir da necessidade da população em agasalhar-se no clima frio da região. Utilizava-se para a criação das peças os poucos recursos disponibilizados na época, seja em termos de mão de obra, instrumentos ou matéria-prima para a criação. A confecção dos agasalhos em lã, portanto, iniciou de forma rústica, tendo em vista a necessidade das pessoas mais pobres, como o peão gaúcho, a disponibilidade da lã como matéria-prima, o fuso, a roca e o tear manual como instrumentos para ajudar na criação das confecções (VARGAS, 2016).

É importante destacar que a ovinocultura é uma atividade tradicional nessa região. Os ovinos são animais com boa adaptação aos campos nativos, os quais possuem vegetação rasteira e de fácil pastejo para a espécie, os animais também se adaptam facilmente ao clima, à vegetação e ao relevo da metade sul do Estado. A criação de ovelhas propicia alto rendimento em pequenas áreas, uma alternativa ao pecuarista familiar e à permanência das famílias no campo. O rendimento da criação decorre da comercialização do borrego, da ovelha para o abate e da lã destinada à confecção de peças de forma artesanal. A fibra animal, extraída mediante a tosquia ou a esquila, é um importante elemento na construção do saber-fazer artesanal feminino. A lã é uma matéria-prima de fácil acesso para as mulheres em razão da abundante criação de ovinos no local e em todo o território sulino.

As técnicas artesanais com a utilização da lã são historicamente atribuídas às muIheres. Dentre as várias atividades exercidas pelo sexo feminino, destacam-se os afazeres domésticos, o cuidado com a casa e com a família, "internalizados", embora de uma forma impositiva e cultural do estado sulino, como responsabilidade exclusiva delas (PAIXÃO; EGGERT, 2011). Nesse sentido, as mulheres desenvolveram várias capacida- 
des, dentre as quais a arte de lavar a lã, realizar a cardagem da fibra animal, fazer o fio e tecer as peças, confeccionando, assim, vestes e demais artefatos de caráter utilitário para o uso cotidiano da família.

Com o passar do tempo, entretanto, tais atividades foram ressignificadas no Estado. No cenário contemporâneo, os produtos artesanais em lã, couro, madeira ou confeccionados a partir de outras matérias-primas, passaram a ser valorizados no mercado simbólico dos chamados produtos culturais e gauchescos. Nesse sentido, o artesanato vem ganhando uma nova conotação. As peças artesanais, por vezes denominadas de rústicas pelos consumidores, passaram a ser valorizadas por um mercado identificado com a cultura gaúcha, frequentado por turistas e/ou por consumidores que atribuem simbolismos a estes artigos, conferindo aos mesmos identidade e referência cultural e simbólica ao território.

\section{IDENTIDADE CULTURAL E MERCADO SIMBÓLICO DOS PRODUTOS ARTESANAIS NO TERRITÓRIO DO PAMPA}

Tanto para Raffestin (1993) quanto para Lefebvre (1976), é a partir da produção do espaço que se constroem os territórios; assim, as bases de interpretação dessa construção estão pautadas na relação homem e natureza. Dessa maneira, tanto reconhecem que o espaço é dotado de uma realidade material preexistente quanto um campo de possibilidades de ação social, cultural e simbólica. Nesse sentido, a abordagem territorial em questão procura reconhecer a imbricação entre materialidade e imaterialidade (SANTOS; DAVID, 2018). Ambas ações - material e imaterial - compõem o modo de vida dos indivíduos de cada território e formam as territorialidades específicas de cada espaço.

Na concepção de Haesbaert (2004), o território pode ser interpretado a partir de três vertentes básicas: política - quando o território é analisado como um espaço delimitado e controlado, por meio das relações de poder político, seja do Estado ou de outros agentes; econômica - em que se destaca a relação de embate entre as classes sociais e na relação de capital-trabalho; e a cultural - na qual se prioriza a dimensão simbólica e mais subjetiva pelo contexto do território.

A compreensão de território inclui sempre uma ou algumas territorialidades específicas, mas esta não envolve o território, obrigatoriamente (HAESBAERT, 2004). Segundo o autor, a territorialidade configura-se como uma condição genérica para a existência de um território, pois enfatiza a sua dimensão simbólico-identitária. A construção dos símbolos e das identidades passa por uma relação muitas vezes produzida por processos culturais híbridos, uma vez que os sujeitos são dinâmicos, se deslocam e passam por variados tipos de influências, seja em termos geo-históricos e/ou socioculturais.

De uma forma geral, a questão cultural, para Schein (2001), faz parte de todos os grupos sociais; todos os indivíduos são dotados de cultura, pois fazem parte de um contexto global e multicultural. A cultura dos diferentes grupos sociais tem sido compartilhada por intermédio do comportamento, da confecção de produtos, da forma de organização, da transmissão de conhecimentos e experiências. Assim, para o autor, a cultura representa um conjunto de formas coletivas e intrinsecamente ligadas ao comportamento dos sujeitos. 
Os territórios rurais têm sido reconhecidos no âmbito dos estudos acadêmicos, especialmente nas ciências sociais, na questão da confecção dos produtos artesanais. Esse trabalho, dotado de saberes e práticas culturais tradicionais, tem utilizado predominantemente elementos naturais que expressam a relação com o espaço onde os artesãos, muitas vezes também agricultores(as), estão inseridos (MELLO; FROEHLICH, 2015), demonstrando uma correlação com seus valores, histórias e com suas identidades.

Mediante os saberes e fazeres revelam-se as novas estratégicas dos grupos sociais rurais e as dinâmicas com os saberes tradicionais das comunidades rurais, bem como as inter-relações sociais, culturais, econômicas e ambientais que derivam desse processo (TEDESCO, 2018). O processo artesanal, junto a agricultura familiar e/ou camponesa, configura-se na reconstituição e na otimização de processos tradicionais inseridos nos horizontes da modernidade econômica, em um mercado de produtos simbólicos.

Assim, o fazer artesanal é notadamente um saber cultural das comunidades rurais do pampa gaúcho. Embora com agregação de novos conhecimentos, os produtos das habilidades manuais de homens e mulheres refletem técnicas tradicionais desse território. São considerados saberes que se perpetuam no tempo, os quais remetem à memória e produzem uma identidade dos sujeitos envolvidos, formando o patrimônio cultural da região. O "artesão produz a partir de uma cultura, e o produto que faz, o objeto artesanal, tem esse duplo caráter: é uma mercadoria por um lado, mas é também um produto cultural resultante do significado da vida daquela pessoa" (LIMA, 2011).

A identidade cultural pampiana, observada nas contribuições de Rieth e Lima (2018) e Rieth et al. (2014), é construída, em boa medida, pela paisagem pampiana, na qual a pecuária extensiva e a criação de bovinos e ovinos, dão sentido à identidade do gaúcho, onde os elementos homem, animal, campo (cerros, serras, vales e coxilhas), estão intimamente interligados, produzindo e reproduzindo saberes, fazeres e memórias, com base nestas relações.

Nesse sentido, dentro da identidade cultural desse espaço são notáveis os saberes e os fazeres tradicionais, como as "lidas campeiras" e os processos artesanais em lã e couro. O ambiente da pecuária familiar propicia a construção dessas identidades, do guasqueiro (artesão que trabalha com o couro, produzindo peças para o uso do gaúcho, do homem que trabalha na lida com o gado) e da artesã, por exemplo, em virtude de que muitos desses conhecimentos estão enraizados nas famílias, em suas vivências e nas memórias do passado.

Esse discurso é aprimorado por Rieth et al. (2014), quando apresentam a pesquisa do Inventário Nacional de Referências Culturais (INRC) - As lidas campeiras na região de Bagé/RS: sobre as relações entre homens, mulheres, animais e objetos na invenção da cultura campeira -, investigação cujo objetivo foi identificar e documentar o trabalho na pecuária extensiva do pampa sul-rio-grandense como referência cultural desta região, tornado patrimônio imaterial brasileiro.

Parte desses saberes, agora considerados patrimônio imaterial, estão relacionados à "doma dos animais", à "feitura do aramado", ao ofício do guasqueiro, à "esquila ou tosquia" dos ovinos, que são, geralmente, trabalho do homem (RIETH; LIMA 2018, p. 99), enquanto as mulheres realizam a "lida caseira" nas proximidades da casa, os afazeres domésticos e, muitas vezes, a confecção artesanal de artigos em lã. A esquila, assim 
como a confecção das peças em lã, geralmente tornam-se atividades alternativas e de complementação de renda da família e representam a forte relação dos saberes culturais com a natureza, ou seja, com os aspectos da biodiversidade do local.

É possível considerar, portanto, que o artesão no espaço rural do pampa possui habilidades, que são resultado de uma interação entre os seres que ali habitam bem como desses seres com o ambiente. Nessa interação, a criação desses artigos possui fatores sociais, culturais, simbólicos e técnicos relacionados ao aprendizado do fazer (CANCLINI, 1983), expressos na concentração, na sensibilidade, no agir, no observar, no tramar, na transformação da matéria-prima que possui disponível, em uma prática, em uma peça e, ainda, na preocupação de inserir esse produto num mercado.

Na questão do mercado simbólico, é Bourdieu $(2002,2007)$ quem abre luz ao conceito. A confecção desses elementos simbólicos obtém esse sentido quando foram compreendidas as diferenças em relação a outros produtos, pois a elas são atribuídas significações. Os consumidores, reconhecendo o aspecto simbólico, legitimavam os artigos e seu consumo perante a sociedade, contribuindo para a criação de um "sistema de produção e circulação de bens simbólicos", definido por Bourdieu (2007, p. 105) "como sistema de relações objetiva entre diferentes instâncias, definidas pela função que cumprem na divisão do trabalho de produção, de reprodução e de difusão de bens simbólicos".

O espaço do mercado simbólico do artesanato, como pode ser o caso das tendas, configura-se como um local dotado de valores materiais e representativos, os quais aperfeiçoam a comercialização. Os símbolos são instrumentos necessários ao conhecimento e à comunicação; são eles que "tornam possível o consenso acerca do sentido do mundo social que contribui, fundamentalmente, para a reprodução da ordem social" (BOURDIEU, 2002, p. 10). Segundo o autor, estes elementos são instrumentos fundamentais para a integração lógica, pois possibilitam um sentido às atividades individuais e coordenam as ações estabelecidas com os outros.

Conforme o autor, as simbologias estão atreladas às vivências e às memórias dos indivíduos. Os consumidores, reconhecendo o aspecto simbólico, legitimavam os artigos e seu consumo perante a sociedade, contribuindo para a criação de um "sistema de produção e circulação de bens simbólicos", definido por Bourdieu (2007, p. 105) "como sistema de relações objetivas entre diferentes instâncias, definidas pela função que cumprem na divisão do trabalho de produção, de reprodução e de difusão de bens simbólicos".

Tal processo tem a contribuição da transformação dos sentidos atribuídos aos objetos, os quais passam de uma realidade material para uma realidade imaterial. O simbolismo que a peça representa ao ser acionado pelo imaginário das pessoas, transporta sentidos para o tempo presente, quando novos valores e significados podem the ser atribuídos (TEDESCO, 2018). Para o autor, são estes os fatos que fazem com que os objetos tenham poder, pois acionam o imaginário e a memória dos sujeitos, proporcionando significados.

O artesanato em lã produzido no pampa, por exemplo, é materializado por meio de práticas, expressões, formas de fazer e produtos que remetem à história do lugar onde vivem os sujeitos. Nesse território, ele enfatiza dinâmicas produtivas e reproduz 
o legado de um patrimônio cultural produzido no meio rural, fazendo uso contemporâneo de elementos tradicionais, do conhecimento de técnicas aprendidas no passado e dos elementos da paisagem, tal como a matéria-prima disponível - a lã ovina (VARGAS, 2016).

Toda essa movimentação gera uma sinergia em torno dos produtos e dos serviços ofertados no território do pampa, configurando um consumo simbólico. Os símbolos são elementos que possuem um significado atribuído, uma referência história e/ou cultural, do modo de vida e/ou da paisagem e são essas as características que colocam produtos e serviços em um cenário de comercialização simbólica (BOURDIEU, 2002). Dessa forma, o mercado simbólico representa a relação comercial em um espaço como algo dotado de valores materiais e representativos, os quais aperfeiçoam a comercialização.

São estas questões que constroem e fortalecem a identidade cultural da sociedade de um determinado local. São os elementos históricos, culturais e simbólicos, alguns materializados, como as peças artesanais, e outros não, como o sentimento de pertencimento ao lugar, que criam singularidades, sinergias e constroem o sentido de identidade das comunidades e o cenário para a estruturação de um mercado de produtos simbólicos.

\section{DINÂMICAS COMERCIAIS DO ARTESANATO NA COMUNIDADE DA VILA PROGRESSO}

A principal dinâmica econômica da comunidade Vila Progresso em Caçapava do Sul-RS está pautada em torno da criação e da comercialização dos produtos artesanais tradicionais, culturais e simbólicos do território do pampa. Destaca-se, nesse sentido, especialmente a produção em lã criada pelos artesãos do local e demais artigos em couro, madeira e coloniais, ${ }^{4}$ confeccionados ou adquiridos na região para serem vendidos nas tendas artesanais da comunidade.

Para compreender a lógica de desenvolvimento desse mercado simbólico no local, será apresentado, a seguir, um breve histórico da estruturação do comércio artesanal no local, bem como o cenário atual da comunidade e das tendas comerciais; será comentada, ainda, a necessidade de diversificação dos produtos e o surgimento de estratégias multidimensionais com o aprendizado do artesanato em madeira e a inserção de produtos alimentares produzidos a partir dos saberes dos sujeitos do local e dos elementos do território, tendo em vista a observação dos interesses dos consumidores.

A comercialização dos produtos artesanais nesta comunidade rural está ligada a elementos favoráveis para o seu desenvolvimento, tais como os históricos, culturais e geográficos já citados neste texto, e a localização privilegiada do núcleo de artesãos, às margens da BR-290 (VARGAS; FIALHO, 2018). Este fato favorece a divulgação e a venda dos artigos em virtude do constante fluxo de turistas e demais viajantes, inclusive

\footnotetext{
${ }^{4}$ São produtos confeccionados e processados a partir de saberes tradicionais das comunidades rurais, muitas vezes de forma artesanal, nos quais estão presentes suas memórias, vivências, história, cultura e, enfim, elementos de um modo de vida que são colocados na produção dos artigos coloniais, os quais passam a ter atributos culturais de determinada comunidade ou território.
} 
uruguaios e argentinos, os quais prestigiam os produtos artesanais com forte tradição cultural do pampa, e ainda, viajantes a serviço do comércio que passam pela região (PETRIN; CARMO DA SILVA, 2013).

Caçapava do Sul está localizada na serra do Sudeste, pertence ao Corede da Campanha, possui uma área de $3.047,20 \mathrm{~km}^{2}$ e sua população estimada, em 2010 , é de 33.650 habitantes, dos quais $60 \%$ encontram-se no meio urbano e $40 \%$ no espaço rural. Distante $250 \mathrm{~km}$ de Porto Alegre, a economia é basicamente sustentada pela mineração, agricultura e pecuária (PREFEITURA, 2014). Localiza-se, portanto, na Metade Sul do Estado, conhecida como a região menos dinâmica do Rio Grande do Sul e também pela relevância da criação agropecuária, especialmente de bovinos e ovinos (como pode ser analisado na Tabela 1).

De acordo com dados do Censo Agropecuário (IBGE, 2017), Caçapava do Sul possui um Produto Interno Bruto (PIB) de R\$ 699.360,99, em que o segmento da agropecuária responde por $\mathrm{R} \$ 104.851,91$, representando cerca de $15 \%$ do PIB total. Segundo dados do mesmo censo, Caçapava do Sul é o nono município do Estado com maior produção de bovinos, e tendo cerca de mil estabelecimentos agropecuários produzindo ovinos.

Esses dados reforçam a importância da produção e comercialização pecuária no município, não somente da carne, mas dos subprodutos como a lã e o couro, bem como os produtos artesanais confeccionados a partir dessas matérias-primas, gerando economia e desenvolvimento para a região, assim como saberes e fazeres manuais do artesanato de cunho regional ou de identidade cultural e territorial, quando a Vila Progresso se destaca como a comunidade mais dinâmica nesse sentido.

Tabela 1 - Panorama da agropecuária em Caçapava do Sul

\begin{tabular}{|l|c|}
\hline \multicolumn{1}{|c|}{ Dados Agropecuários } & Números \\
\hline Estabelecimentos agropecuários & 2.653 \\
\hline Mão de obra ocupada na agropecuária & 6.180 \\
\hline Ovinos (cabeças) & 53.588 \\
\hline Bovinos (cabeças) & 178.911 \\
\hline
\end{tabular}

Fonte: Elaborada a partir dos dados do IBGE/Censo Agropecuário, 2017.

Importante destacar, ainda, que a Prefeitura de Caçapava do Sul, por intermédio da Secretaria de Agricultura e Pecuária, apoia o artesanato em lã da Vila Progresso, fornecendo transporte gratuito para os(as) artífices se deslocarem com seus produtos para as feiras agropecuárias que ocorrem no Estado. Além disso, em parceira com o Sindicato dos Trabalhadores Rurais (STR), os artesãos conseguem espaço de exposição nas feiras junto ao ambiente da agricultura familiar, sem custos de aluguel de estandes.

Em relação à história do artesanato em lã na comunidade, percebe-se que o fator da localização foi o que motivou as primeiras mulheres artesãs, pertencentes a uma mesma família, a se instalaram na comunidade há pouco mais de três décadas. Tal fato, datado da década de 80 do século 20, constitui-se em um desafio para as artesãs, uma vez que a localidade possuía apenas um armazém e poucos moradores (casas). A partir dessa iniciativa, as artífices passaram a vender as peças que confeccionavam: palas, cobertores, boinas, pelegos, xergãos (mantas de lã batida) e demais artigos. Essas mulhe- 
res residiam em localidades próximas; "nós já produzíamos peças em lã, principalmente os palas e vendia sob encomenda para os vizinhos, alguém da família e na cidade" (Artesã I-3).

Uma das pioneiras da atividade artesanal na comunidade destaca como foi estabelecida a primeira estratégia comercial no local. A artífice relata que ela, a mãe e a irmã confeccionavam vários tipos de peças em lã: "no início da comercialização não tínhamos nenhuma estrutura no local para expor os produtos" (Artesã N-2). A artesã relata, ainda, que o terreno onde residiam possuía um relevo elevado em relação à rodovia, e os consumidores precisavam fazer um esforço físico para comprar as peças. "Quando começamos não tinha feito os bueiros ainda, a gente colocava as peças em cima do barranco, o pessoal subia e descia, colocava os palas pendurados em uma árvore que tinha na frente da casa" (Artesã N-2). Evidencia-se, nesta fala, as primeiras iniciativas que originaram o mercado de produtos artesanais e simbólicos, ao exporem seus produtos nas proximidades da BR. As primeiras experiências com o mercado possibilitaram um processo de autoconfiança diante do seu saber-fazer, do conhecimento tradicional e da prática da atividade artesanal das artesãs, além de mostrar a existência de um mercado para os produtos que produziam nas horas vagas.

Essas experiências também proporcionaram uma consciência social da ligação da mulher com o artesanato, a qual acontece em razão da produção habilidosa das mãos femininas e, ainda, uma perspectiva de afirmação de que os trabalhos manuais, realizados muitas vezes no âmbito doméstico, pode sim ser de interesse comercial (PAIXÃO; EGGERT, 2011). Com a abertura de novos espaços comerciais no cenário contemporâneo, as mulheres evidenciaram para a comunidade que devem ser reconhecidas como portadoras de um conjunto de saberes tradicionais, aos quais se deve atribuir valor e importância social e econômica.

As autoras realizam essa reflexão sobre um contexto mais abrangente da produção artesanal praticada por mulheres, mas tais ponderações se refletem aqui no sentido de que as primeiras iniciativas, seja de confecção ou de comercialização das peças em Iã na comunidade da Vila Progresso, foram realizadas por mulheres, as quais carregavam consigo saberes tradicionais que perpassaram gerações. Essa comercialização, por muito tempo, não possuía significativo valor econômico. Somente com a valorização cultural e identitária dos produtos tradicionais gauchescos, o mercado destes produtos evoluiu. Assim, os saberes tradicionais praticados por elas começaram a adquirir valor econômico.

No cenário contemporâneo, de acordo com o presidente da associação de moradores da comunidade, "são 68 famílias residindo no local, são pequenos agricultores, aposentados e artesãos". As propriedades, na localidade, possuem "aproximadamente 1,5 hectares". Algumas destas famílias possuem outras áreas em localidades próximas, onde cultivam produtos agrícolas para a subsistência e criam animais para o consumo. Existem casos, em menor número, de famílias que possuem áreas arrendadas destinadas à produção de soja, arroz ou criação de gado

Atualmente são 16 famílias de artífices na comunidade e cada uma delas possui uma tenda artesanal na beira da BR-290, posto que essas tendas se configuram nos pontos comerciais para a venda dos artigos artesanais, gerando em torno de 40 empregos diretos e indiretos, entre homens, mulheres, jovens, adultos e idosos. $\mathrm{O}$ trabalho 
artesanal em lã no local possui "picos de produção e comercialização na época de outono-inverno", já "no período de primavera-verão a comercialização diminui e o comércio na comunidade passa a girar em torno dos produtos gauchescos em couro e madeira" (Artesão J-6).

Além de seus integrantes, é comum as famílias terem de recorrer ao trabalho de outros moradores da localidade, principalmente das mulheres, que contribuem para 0 acabamento das peças em lã, e dos jovens, que realizam a confecção dos tecidos nos teares. Estes são contratados de forma temporária, sendo fundamentais para o processo de produção das peças em lã. Em alguns casos, parte considerável da confecção dos produtos em lã é realizada pelas mãos dos artesãos contratados, uma vez que os proprietários dos estabelecimentos comerciais precisam estar atentos ao comércio das peças à margem da BR, cujo cenário pode ser visualizado na Figura 2.

É importante considerar que a comunidade não trabalha em forma de cooperativa. Os donos das tendas são os artesãos, os quais possuem a função de cuidar dos estabelecimentos (do comércio das peças artesanais) e da confecção dos artigos em lã. A mão de obra contratada é fundamental, especialmente para a confecção das peças. Além disso, a geração de empregos no local, mesmo que seja de forma temporária, contribui significativamente para o rendimento econômico de boa parte dos jovens da comunidade, os quais possuem um trabalho intenso com a tecelagem nos períodos de outono e inverno. Alguns jovens relatam que nesse período chegam a receber o valor monetário de até dois salários mínimos ao trabalhar nas tendas da comunidade.

Percebe-se, nesse sentido, que a exploração dos saberes e fazeres artesanais e a construção de estratégias comerciais, como as estruturas das tendas na "beira da estrada", são ações alternativas de trabalho e renda no meio rural que configuram cenários do rural para além do agrícola, onde as famílias, com poucos recursos econômicos e pequena área de terra, fazem uso de seus saberes para construir uma alternativa rentável e assim conseguir manter-se no meio rural (TEDESCO, 2013; CANCLINI, 1983).

Como, porém, se estrutura essa dinâmica comercial nas tendas? O fato de ter um comércio aberto implica organizar o ambiente da tenda e atender aos consumidores que visitam o local. Os artífices precisam arrumar os locais de comercialização e os varais que são colocados em frente às residências, e negociar com os fornecedores que se dirigem ao local para vender ou trocar produtos. De uma forma geral, as mulheres artesãs estão mais voltadas à produção das peças - a "agency" do produto é responsabilidade delas -, enquanto o homem cuida das vendas nas tendas. Já a organização do espaço da tenda é trabalho de ambos.

Na organização do trabalho artesanal e comercial, as tendas são pontos de venda que se configuram como circuitos curtos de mercado e como alternativas de comercialização e renda para agricultores familiares ou camponeses, que encontram no artesanato praticado no espaço rural uma fonte de renda.

São valores materiais e imateriais atribuídos ao mesmo produto. Ainda, são essas tradições locais que se constituem por meio dos produtos artesanais, que reforçam correlações identitárias do produto e acabam por produzir e otimizar redes mercantis tra- 
dicionais, mediante a venda direta ao consumidor (CERDAN; VITROLLES, 2008). Tal ação cria uma reciprocidade e novas sociabilidades entre produtor (artesão) e consumidor, estabelecendo vínculos culturais e sinergias sociais.

Figura 2 - Tendas artesanais na Vila Progresso

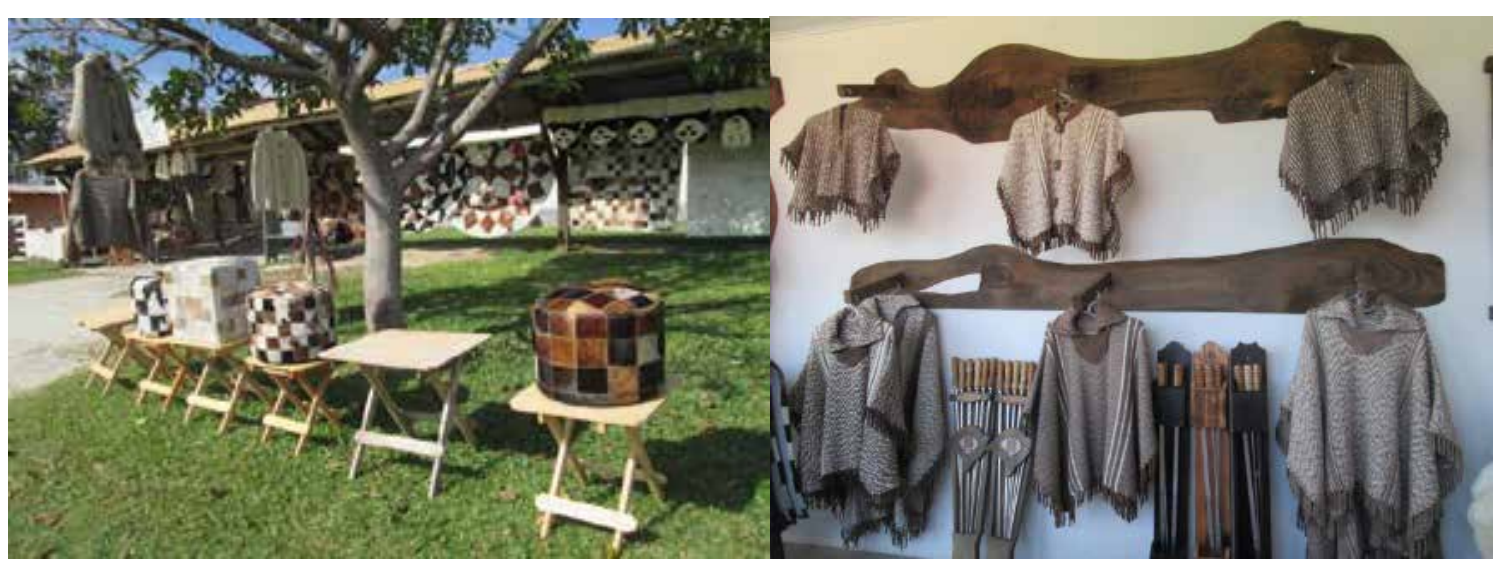

Fonte: Pesquisa de Campo na Vila Progresso, 2016.

Tendo em vista o cenário da concorrência entre os artesãos - tendeiros - em razão da proximidade dos pontos de vendas, vem ocorrendo no local a busca pela diversificação de produtos artesanais e de cunho simbólico gauchesco. Essa diversificação ocorre, muitas vezes, pela troca das confecções em lã, criadas pelos artífices, por outras peças, principalmente em couro e madeira. Essa foi uma estratégia encontrada pela comunidade para conseguir manter artigos diferenciados disponíveis nas tendas sem, necessariamente, pagar o valor em dinheiro no momento da transação.

A troca de produtos é uma estratégia que facilita o negócio e diversifica os objetos ofertados ao consumidor. Abriu-se um espaço para que produtos vindos de fora fossem comercializados no local, os quais são comprados ou trocados com outros artesãos, lojas ou revendedores que circulam pela BR 290. Esse fato comprova a busca por estratégias de diversificar os produtos para atrair o olhar do consumidor, aproveitando o cenário próprio para a expansão comercial dos artigos simbólicos e de referência cultural.

Por outro lado, a necessidade da diversificação de artigos para serem comercializados no local também abriu oportunidades para que pessoas da comunidade passassem a buscar novos saberes ou resgatar saberes "adormecidos. Alguns "jovens passaram a criar peças artesanais em madeira", quadros de fotografia e souvenir para decoração, "utilizando madeira de demolição encontrada na região" (Artesão A-4).

Nesse sentido, Vives (1983) destaca que o artesanato não é algo fragmentado; os produtos confeccionados têm uma relação com a vida da comunidade que os produz. Percebe-se o contexto mencionado pela autora ao analisar que, na comunidade citada, alguns sujeitos estão redescobrindo ou revalorizando saberes manuais que pareciam esquecidos. Esse fato está intimamente ligado ao mercado, quando os consumidores passam a valorizar produtos confeccionados de forma tradicional e que apresentam elementos de um saber territorializado. 
Canclini (1983), por sua vez, argumenta que tem se expandido, em âmbito global, espaços de comercialização de produtos artesanais, atraindo turistas e gerando renda ao artesão. Produtos que estavam fadados ao desaparecimento ressurgem com força, abrindo espaço para técnicas tradicionais, como a tecelagem, a cardagem ${ }^{5}$ e o trabalho em couro, realizados por artífices homens e mulheres.

Além destes, duas famílias de tendeiros buscaram o aprendizado da criação de pequenas mesas, cadeiras, bancos e porta-churrasco em madeira, tendo em vista oferecer produtos rústicos e autênticos aos consumidores que passam pelo local. Essa ação deu origem a duas pequenas marcenarias junto as tendas. São conhecimentos que passam a ser dinamizados no mercado, diferenciando o comércio local e reforçando a identidade cultural da comunidade.

Também têm surgido na comunidade trabalhos manuais realizados pelas mulheres, como artesanato em patchwork, crochê e tricô e a elaboração de produtos coloniais, como queijos, doces, pães e bolos. Tais produtos são comercializados com alguns dos tendeiros da comunidade, especialmente aqueles que têm investido na ampliação de seus pontos comerciais para além de produtos estritamente artesanais em lã. São saberes domésticos, fazeres locais, tradicionais e que estão ligados aos aspectos culturais do território (TEDESCO, 2013). Enfim, são práticas do cotidiano e que se tornam produtos simbólicos de determinado espaço.

O que pensam os artífices sobre tais questões? Um dos artesãos entrevistados destaca que os produtos diferentes, aqueles que não são confeccionados em lã, comprados ou trocados, estão relacionados à concorrência estabelecida entre os comerciantes do local, com o aumento do número de tendas e a diminuição do frio nos últimos anos. Para o artesão, "não temos mais aqueles invernos rigorosos; então começou a diminuir as vendas dos palas e aí começaram a colocar outras coisas; às vezes o cliente vai numa tenda, vai em outra e quem baixa um pouquinho mais o preço consegue vender" (Artesão R-5).

De acordo com a narrativa do artesão, nos anos em que o inverno não é muito rigoroso, com poucos dias consecutivos de frio, é normal que a comercialização das peças em lã oscile. Aliado a este fato, a diversificação dos produtos comercializados nas tendas começou a acontecer em decorrência da demanda dos consumidores, e, ainda, o fato de um artesão-tendeiro buscar um produto novo para a tenda, torna-se um incentivo para o outro tendeiro trazer o mesmo produto; são as leis da concorrência entre eles e do próprio contexto mercadológico, a que se refere Bourdieu (2007).

\footnotetext{
A tecelagem e a cardagem são técnicas que possuem datas imprecisas, mas no Rio Grande do Sul, segundo Côrtes ([1985?]), tais atividades manuais parecem ter começado a ser praticadas pelos indígenas, sendo aprimorada pelos jesuítas e também pelos portugueses. De toda a forma, a história destas técnicas manuais precisa ser buscada nas entrelinhas das pesquisas, que, muitas vezes, não possuem dados precisos sobre o assunto. Os primeiros teares manuais de que se tem notícias podiam ser de posição vertical ou horizontal, sendo utilizados para confecção de peças do vestuário e demais utensílios necessários para a vida doméstica (SANTOS, 2005). Já a cardagem está associada ao fazer o fio de lã para ser tecido, ser aproveitado na tecelagem. A cardagem e a tecelagem, portanto, são atividades associadas no fazer artesanal em lã. O processo de cardar os fios consiste em passar uma espécie de tábua com alguns pregos de aço sobre os meados de lã; esta etapa proporciona que a lã seja separada em mechas. Para se obter o fio é necessário que estas mechas sejam passadas de forma manual no fuso ou mecânica na roca, a qual pode ser movida a pedal ou a mão (CÔRTES, [1985?]).
} 
Os principais produtos em lã confeccionados pelos artesãos do local são: palas para adultos e crianças, capinhas femininas, cobertores, tocas, golas, boinas, meias, mantas, luvas, pelerines, xales, xergãos e pelegos. Além destes, são comercializados no local artigos comprados e/ou trocados com fornecedores por peças em lã como: tapetes, puffs e bancos em couro, bancos e mesas rústicas em madeira, chinelos em couro e ovelhinhas de lã, relógios e gamelas em madeira, caixas de MDF forradas e decoradas, facas, mateiras em couro, cuias, bombas de chimarrão e vários itens de decoração em lã, couro ou madeira. A diversidade nas tendas do local pode ser visualizada na Figura 3.

Figura 3 - Diversidade de artigos artesanais nas tendas da Vila Progresso

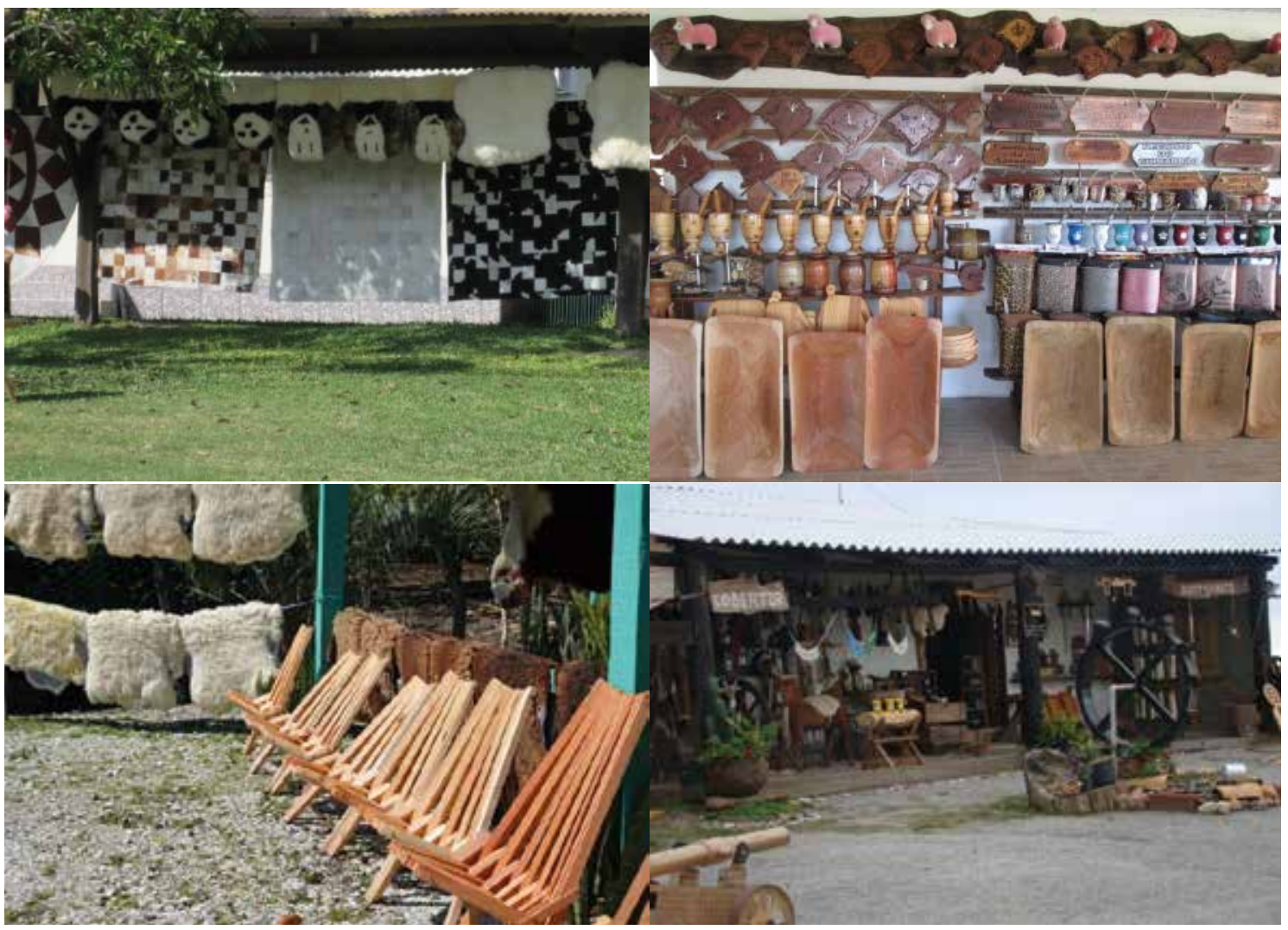

Fonte: Pesquisa de Campo na Vila Progresso, 2016.

Tedesco (2013), ao escrever sobre os cenários dos tendeiros da Rota das Salamarias, região nordeste do Rio Grande do Sul, destaca que o fato de ofertar mais produtos nos pontos comerciais faz parte de uma dinâmica de mercado adotada pelos tendeiros, o qual denomina de oferta diversificada. Mesmo que se referindo a outros contextos, Bourdieu (2007) destaca que o mercado das trocas simbólicas é produto de uma construção social, devendo, portanto, ser compreendido para além da visão econômica, relacionada a questões de oferta e demanda do mercado. Segundo o autor, nesse campo econômico precisa-se analisar as disponibilidades econômicas imediatas e a instantaneidade das interações sociais.

Interpretando a análise de Bourdieu (2007), o mercado dos produtos artesanais, objeto do presente estudo, também é construído socialmente em razão da demanda dos consumidores e das estratégias criadas pelos artesãos para satisfazer essas demandas, as quais são construídas a partir das relações. Fruto destas interações, são estabelecidas as estratégias em torno dos novos produtos, em que a relação entre artífices e consu- 
midores gera uma estrutura de campo e vários fatores aparecem, seja em virtude das demandas ou das alternativas construídas pelos artífices para obter produtos novos e comercializar os mesmos e, ainda, a competição com o ponto comercial ao lado.

Percebe-se que a diversificação nas tendas da comunidade tem por objetivo atingir os consumidores que buscam objetos rústicos, autênticos e tradicionais, em razão de uma aproximação com o modo de vida do campo, fatores que atraem o turista. Canclini (1983) lembra que o produto artesanal rústico atrai os turistas que vêm de fora e precisam levar algo que represente para o seu contexto social o lugar em que ele esteve, onde manteve contato com a cultura. $O$ autor lembra que os turistas possuem uma fascinação pelo nostálgico, rústico e natural, uma das motivações mais invocadas pelo turismo.

\section{CONSIDERAÇÕES FINAIS}

Analisando o estudo realizado na Vila Progresso, percebe-se que existe na comunidade um contexto comercial onde os produtos artesanais estão em movimento, conectando coisas, pessoas, lugares e culturas; fatores que acabam por influenciar mudanças no aspecto produtivo e comercial das peças, transformando o sentido de uso dos produtos, a estruturação dos pontos comerciais e as dinâmicas de trabalho nas tendas.

É importante relembrar que o surgimento das dinâmicas comerciais no local, hoje bastante diversificada em virtude do crescimento do mercado simbólico dos produtos gauchescos, ocorreu por intermédio das confecções em lã e pela iniciativa de uma família de mulheres artesãs. Foi por meio dessa ação que a comunidade deu início a um processo de produção artesanal com forte identificação com a cultura gaúcha e, consequentemente, o desenvolvimento do mercado de produtos artesanais. Esse processo levou a uma ampliação do número de famílias dedicadas a essa atividade, resultando, de acordo com relatos, no aumento da população no local, na diversificação dos produtos comercializados e na geração de empregos na atividade, além de uma melhor organização estrutural da comunidade.

A partir do momento em que os primeiros pontos comerciais começaram a obter rentabilidade, outras famílias foram atraídas para o local, primeiramente para se tornarem mão de obra dos artesãos ali estabelecidos e, num segundo momento, abriram seu próprio ponto comercial de produtos artesanais. Atualmente, é preciso destacar a diversificação de produtos artesanais no local. As peças em lã continuam sendo o carro-chefe, com destaque para a comercialização no período de inverno. Nos demais meses do ano, os produtos em couro e madeira ganham maior visibilidade e oportunizam melhor rendimento aos artesãos-tendeiros. Nos últimos anos essa dinâmica tem despertado para novos saberes artesanais, com a produção na comunidade de peças em madeira, artesanato doméstico e produtos coloniais.

Dessa forma, as observações realizadas na comunidade nos permitem acreditar que os simbolismos dos produtos artesanais são capazes de acionar memórias coletivas, tanto pelos artesãos, os quais foram capazes de reproduzir seus conhecimentos e os saberes de outros, realizados no passado, quanto pelo sujeito que compra tais produtos. Assim, entende-se porque o mercado de artigos artesanais cresceu e diversifi- 
cou-se com tamanha proporção no local, pelo fato de proporcionar, por meio do resgate da história, da tradição, dos saberes e dos fazeres, um significado representativo para os artigos confeccionados.

Além disso, este estudo procura deixar uma contribuição teórica sobre os aspectos da cultura territorial do pampa, bem como do entendimento e da relevância do artesanato e do mercado simbólico destes produtos para as comunidades rurais e para a região, como elementos identitários e do patrimônio cultural e imaterial desse espaço social.

Enfim, de uma forma geral os principais resultados mostram que a comercialização dos produtos artesanais na comunidade estudada passou por um processo de crescimento e diversificação, tendo em vista a evolução do cenário cultural e simbólico dos produtos artesanais gauchescos, bem como a valorização dos saberes tradicionais no contexto do mercado consumidor. O cenário dos produtos artesanais e das dinâmicas comerciais encontrados na Vila Progresso, demonstram que o modo de fazer artesanal, os valores, as técnicas, as formas de trabalho, de comercialização, a sociabilidade, a reciprocidade e a construção de identidades dentro da agricultura familiar e/ou camponesa, partem do saber, do fazer, da tradição, da cultura e da interação dos sujeitos com os elementos naturais de cada território.

\section{REFERÊNCIAS}

BOURDIEU, P. A economia das trocas simbólicas. Vários tradutores. 6. ed. São Paulo: Editora Perspectivas, 2007. p. 361.

BOURDIEU, P. A dominação masculina. Tradução Maria Helena Kühner. 2. ed. Rio de Janeiro: Editora Bertrand Brasil, 2002. 160p.

CANCLINI, N. G. As culturas populares no capitalismo. São Paulo: Editora Brasiliense, 1983.

CERDAN, C.; VITROLLES, D. Valorisations des produits d'origine: contribution pour le développement durable dans la Pampa Gaucha au Brésil. Geocarrefour, n. 83, v. 3, p. 191- 202, 2008.

COELHO, E. P. Baú campeiro: artesanato em couro cru. Porto Alegre: Fundação Gaúcha do Trabalho, [2009?]. (Mão Gaúcha, v. 2).

CORTÊS. J. C. P. O gaúcho: danças, trajes, artesanato. Porto Alegre: Garatuja, [1985?]. 376 p.

DOUGLAS, M.; ISHERWOOD, B. O mundo dos bens: para uma antropologia do consumo. Tradução Plinio Dentzien. Rio de Janeiro: Editora UFRJ, 2006. 306 p.

FAGUNDES, A. A. Curso de tradicionalismo gaúcho. Porto Alegre: Martins Livreiro, 1995.

FILHO, C. S. D. Produção, distribuição e consumo dos bens simbólicos: uma reflexão sobre os programas de apoio ao artesanato. ENCONTRO DE ESTUDOS MULTIDISCIPLINARES EM CULTURA, 5., 2009, Salvador. Salvador, Bahia, Brasil: Faculdade de Comunicação, Ufba, 2009. Disponível em: www.cult.ufba.br/enecult2009/19543.pd. Acesso em: 29 jun. 2018.

HAESBAERT, R. O mito da desterritorialização: do "fim dos territórios" à multiterritorialidade. Rio de Janeiro: Bertrand Brasil, 2004.

IBGE. Instituto Brasileiro de Geografia e Estatística. Censo agropecuário do munícipio de Caçapava do Sul, 2017. Disponível em: https://cidades.ibge.gov.br/brasil/rs/cacapava-do-sul/pesquisa/24/76693. Acesso em: 3 abr. 2019.

LEFEBVRE, H. Espacio y Política: el Derecho a la Cuidad, II. Barcelona: Ediciones Península, 1976.

LIMA, R. G. Artesanato em debate: Paulo Keller entrevista Ricardo Gomes Lima. In: Revista Pós Ciências Sociais, v. 8, n. 15, jan./jun. 2011. Disponível em: http://www.periodicoseletronicos.ufma.br/index.php/ rpcsoc/article/view/593. Acesso em: 25 jun. 2018.

MELLO, C. I.; FROEHLIC, J. M. Artesanato tradicional rural e desenvolvimento territorial no Brasil - uma análise do estado da arte. In: Revista Antropolítica, Niterói, n. 39, p. 150-182, 2. sem. 2015. Disponível em: www.revistas.uff.br/index.php/antropolitica/article/download/222/pdf. Acesso em: 10 out. 2018. 
PAIXÃO, M.; EGGERT, E. A hermenêutica feminista como suporte para pesquisar a experiência das mulheres. In: EGGERT, E. (org.). Processos educativos no fazer artesanal de mulheres do Rio Grande do Sul. 1. ed. Santa Cruz do Sul: Editora Edunisc, 2011. 108p.

PETRIN, C.; CARMO DA SILVA, M. Jornal do Pampa - Caçapava do Sul. 2013. Disponível em: http://www. farrapo.com.br/noticia/2/4057/A-producao-artesanal-da-Vila-Progresso. Acesso em: 28 mar. 2018.

PREFEITURA de Caçapava do Sul. Dados. 2014.

RAFFESTIN, C. Por uma geografia do poder. São Paulo: Ática, 1993.

RIETH, F. M. S. et al. As lidas campeiras na região de Bagé/RS: sobre as relações entre homens, mulheres, animais e objetos na invenção da cultura campeira. REUNIÃO BRASILEIRA DE ANTROPOLOGIA, 29., 2014. Natal, RN, 2014.

RIETH, F. M. S.; LIMA, D. V.; Manejos pecuários: ofícios e saberes artesanais. In: DAVID, C. D.; VARGAS, D. L (org.). Saberes tradicionais e artesanato: expressões culturais do campo brasileiro. São Leopoldo: Editora Oikos, 2018. p. 87-103.

SANTOS, A. L. M.; DAVID, C. de. Territórios em disputa: expressões da questão agrária na região da campanha gaúcha - um olhar desde São Gabriel/RS. In: MEURER, A. C.; FOLMER, I. (org.). São Gabriel: território da educação do campo. São Leopoldo: Editora Oikos, 2018. 15-36p.

SANTOS, M. L. Do galpão ao salão: o pala gaúcho como referencial na criação de design têxtil. 2005. Monografia (Especialização Design e Estamparia) - Universidade Federal de Santa Maria, Curso de Especialização em Design para Estamparia, Centro de Artes e Letras, Santa Maria, RS, 2005.

SCHEIN, E. H. Guia de sobrevivência da cultura corporativa. Rio de Janeiro: José Olympio, 2001.

SILVA, E, L. Mapa de Localização de Caçapava do Sul-RS. Cartografia. Programa de Pós-Graduação em Geografia, UFSM. Santa Maria, RS, 2018.

TEDESCO, J. C. Saberes e fazeres entre os afazeres: a dinâmica e os sentidos de produtos artesanais entre camponeses do norte e nordeste do RS. ENCONTRO ANUAL DA ANPOCS, GT 20: METAMORFOSES DO RURAL CONTEMPORÂNEO, 36., 2013. Anais [...]. Disponível em: www.anpocs.com/.../36...anpocs/.../ 8068-saberes-e-fazeres-entre-os-afazeres-a-dinami. Acesso em: 13 mar. 2018.

TEDESCO, J. C. Artesanato, territorialidades étnicas e agricultura familiar: dinâmicas socioculturais e mercantis no meio rural: o caso da Rota das Salamarias. In: DAVID, C.; VARGAS, D. L. (org.). Saberes tradicionais e artesanato: expressões culturais do campo brasileiro. Organização Cesar de David e Daiane Loreto de Vargas. São Leopoldo: Editora Oikos, 2018. p. 15-43.

VARGAS, D. L.; FIALHO, M. A. V. Saberes do processo artesanal em lã: O contexto da comunidade rural da Vila Progresso em Caçapava do Sul-RS. In: DAVID, C.; VARGAS, D. L. (org.). Saberes tradicionais e artesanato: expressões culturais do campo brasileiro. Organização Cesar de David e Daiane Loreto de Vargas. São Leopoldo: Editora Oikos, 2018. p. 104-124.

VARGAS, D. L. Tecendo tradição: artesanato e mercado simbólico em uma comunidade rural do pampa gaúcho. 2016. Tese (Doutorado) - UFSM, Programa de Pós-Graduação em Extensão Rural, Santa Maria, 2016.

VIVES, V. de. A beleza do cotidiano. In: RIBEIRO, B. et al. O artesão tradicional e seu papel na sociedade contemporânea. Rio de Janeiro: Funarte; Instituto Nacional do Folclore, 1983. 253p.

ZATTERA, V. B. S. Arte têxtil no Rio Grande do Sul. Caxias do Sul: Editora São Miguel, 1988. 120p. 